\title{
ALGUNAS REFLEXIONES METODOLÓGICAS SOBRE LA HISTORIA CONSTITUCIONAL*
}

\author{
JOAQUÍN VARELA SUANZES-CARPEGNA \\ Catedrático de Derecho Constitucional \\ Universidad de Oviedo
}
SUMARIO
I. Dos perspectivas de la Historia constitu- cional: la normativo-institucional y la doctrinal
II. Las normas y las instituciones constitu- cionales: el texto y el contexto, la per- manencia y el cambio.
III. Doctrinas y conceptos constitucionales: su contenido jurídico
IV. La interpretación de las doctrinas y los conceptos constitucionales: "presentismo" y "adanismo"

Parto de la base de que la Historia constitucional es una disciplina histórica muy especializada, concebida en muy buena medida sub specie iuris, que se ocupa de la génesis y desarrollo de la Constitución del Estado liberal y liberaldemocrático, con independencia de la forma que adopte esa Constitución y de su posición en el ordenamiento jurídico, aunque tanto esa forma como esa posición sean muy relevantes para la Historia constitucional, como se verá más adelante.

Este concepto sustantivo y axiológico de Constitución es, a mi juicio, el que debe tenerse en cuenta para acotar el objeto de la Historia constitucional y para delimitar temporal y espacialmente el constitucionalismo, como fenómeno his-

* Una primera versión de este artículo se publicó, en septiembre de 2007, en el no 8 de la revista electrónica "Historia Constitucional" (http://hc.rediris.es). Antes se había publicado en francés en el n 68 de la "Revue Française de Droit Constitutionnel", octubre de 2006, y en italiano, ese mismo año, en el no 12 del "Giornale di Storia Costituzionale". 
tórico destinado a limitar el Estado al servicio de las libertades individuales, cuya fecha de nacimiento puede establecerse en la Inglaterra del siglo xvII.

Pero no voy a extenderme ahora sobre este concepto de Constitución, que implícitamente se recogía en el artículo 16 de la Declaración de Derechos de 1789 y al que de forma explícita se refiere la doctrina alemana al distinguir entre Konstitution y Verfassung. En esta ocasión voy tan sólo a examinar algunos problemas que plantea el estudio histórico-y, por tanto, la temporalidad-de las normas, de las instituciones y sobre todo de las doctrinas constitucionales.

Como no quisiera que estas reflexiones tuviesen un carácter demasiado abstracto, voy a traer a colación ejemplos muy concretos de la historia constitucional, muchos de los cuales yo mismo he estudiado a lo largo de estos últimos treinta años ${ }^{1}$.

\section{DOS PERSPECTIVAS DE LA HISTORIA CONSTITUCIONAL: LA NORMATIVO-INSTITUCIONAL Y LA DOCTRINAL}

El estudio de la historia constitucional, tanto si se trata de la nacional como de la comparada - esta última, por desgracia, mucho menos atendida- puede llevarse a cabo desde dos perspectivas distintas: la normativo-institucional y la doctrinal. Desde la primera, la Historia constitucional se ocupa de las normas que en el pasado regularon las bases o fundamentos de la organización y funcionamiento del Estado liberal y liberal-democrático, así como de las instituciones que estas normas pusieron en planta: el cuerpo electoral, las asambleas parlamentarias, la jefatura del Estado, el Gobierno, la Administración, los jueces y los tribunales ${ }^{2}$. Desde la segunda perspectiva, la Historia constitucional se ocupa de la reflexión intelectual que tuvo lugar acerca del Estado liberal y liberal-democrático. Una reflexión de la que nació no sólo una doctrina constitucional, sino también un repertorio de conceptos. Una distinción sobre la que volveré después.

De todo lo anterior se desprende que las fuentes de estudio y a la vez de conocimiento de la Historia constitucional son muy variadas. Desde una perspecti-

1 En realidad, la concepción de la Historia Constitucional que voy a exponer aquí se apoya precisamente en esas investigaciones, por lo que considero necesario mencionarlas en las notas a pie de página, pese a ser bien consciente de que las numerosas auto-citas bibliográficas pueden resultar un tanto agobiantes, por lo que pido disculpas desde ahora mismo.

2 Unas instituciones cuya existencia no se agota ni mucho menos en las normas que las crean, ni en las competencias que éstas les atribuyen. En este sentido, mientras para el Derecho Constitucional puede resultar más adecuado hablar de "órgano" que de "institución", para la Historia constitucional ocurre al revés. El concepto de "órgano"-elaborado por la doctrina alemana, de Gerber a Kelsen- pone el acento en la "posición constitucional", en el status normativo, por ejemplo del Parlamento, mientras que el concepto de “institución" - que ocupa un lugar centra en la doctrina de Santi Romano y de Maurice Hauriou-, sin descuidar este status, insiste también, e incluso sobre todo, en su dinámica, y, por tanto, en las convenciones o reglas no escritas desarrolladas en una práctica a veces multisecular-a las que me referiré más adelante-así como en un conjunto de funciones, simbólicas y representativas, no necesariamente reguladas por el derecho. 
va normativo-institucional, comprenden los textos constitucionales-incluidos los proyectos que no llegaron a entrar en vigor, a veces de gran interés ${ }^{3}$, pero también otros textos distintos del documento constitucional, que por la materia que regulan pueden considerarse también constitucionales, como los reglamentos parlamentarios o las leyes electorales, así como las convenciones constitucionales o reglas no escritas, que resultan esenciales para conocer el funcionamiento de las instituciones básicas del Estado, según se insistirá más adelante.

Desde una perspectiva doctrinal, las fuentes de la Historia constitucional son también muy variadas: los diarios de sesiones de los Parlamentos, principalmente cuando éstos tienen un carácter constituyente ( útiles también como fuente de interpretación de las normas), los opúsculos destinados a la más inmediata acción política y los artículos publicados en la prensa, la jurisprudencia de los tribunales y, en fin, las publicaciones de carácter científico, recogidas en revistas especializadas, en manuales, tratados y monografías, esenciales para historiar la génesis y desarrollo de la ciencia del Derecho Constitucional.

Aunque resulta inevitable que el historiador del constitucionalismo centre su atención en una de estas dos perspectivas, lo deseable es que conjugue ambas. Algo que resulta especialmente obligado cuando se estudia el constitucionalismo de los países anglosajones, en donde las doctrinas constitucionales están más estrechamente ligadas a su contexto normativo-institucional que en el constitucionalismo de la Europa continental, al menos en sus comienzos. Pongamos un ejemplo. Mientras el concepto de soberanía del parlamento que sostuvo David Hume a mediados del siglo XvIII era un reflejo del marco jurídicoinstitucional de la Inglaterra de Jorge $\mathrm{II}^{4}$, el concepto de soberanía nacional que defendió Sieyes en su opúsculo sobre el Tercer Estado (1789) o el que, bajo su influencia, defendieron los liberales españoles en las Cortes de Cádiz, se formula al margen y en contra del ordenamiento jurídico-institucional vigente en la Francia de Luis XVI y en la España de Fernando VII. Un ordenamiento, no obstante, que el historiador debe tener muy en cuenta para comprender mejor los conceptos constitucionales revolucionarios 5 .

3 Como pongo de relieve en Proyectos Constitucionales en España, "Revista Española de Derecho Constitucional", no 76, enero-abril, 2006, pp. 297-304, comentario al libro de Ignacio Fernández Sarasola, Proyectos Constitucionales en España, Centro de Estudios Políticos Constitucionales (CEPC), Madrid, 2004.

4 Cfr, mi artículo Estado y Monarquía en Hume, Revista del Centro de Estudios Constitucionales", n 22, Septiembre -Diciembre, Madrid, 1995, pp. 59-90, así como mi largo ensayo La soberanía en la doctrina británica (de Bracton a Dicey), "Fundamentos. Cuadernos monográficos de Teoría del Estado, Derecho Público e Historia Constitucional", n 1. Oviedo, 1998, pp. 87-165. Traducción inglesa: Sovereignity in British Legal Doctrine, en "E- Law, Murdoch University Electronic Journal of Law", vol. 6, n³, September 1999, http://www.murdoch.edu.au/elaw/issues/v6n3/ suanzes63-text.html; e "Historia Constitucional", n 4, Oviedo, Junio 2003, http://hc.rediris.es.

5 Sobre el concepto de soberanía nacional en Sieyes y sobre su influjo en las Cortes de Cádiz, me extiendo en La teoría del Estado en los orígenes del constitucionalismo bispánico (las Cortes de Cádiz), Centro de Estudios Constitucionales (CEC), Madrid, 1982. Vuelvo a estas cuestiones en mi libro El Conde de Toreno (1786-1843). Biografía de un Liberal, prólogo de Miguel Artola, Marcial Pons, Madrid, 2005. 
Por supuesto, no se ajustaría a la realidad olvidar la presencia en el siglo XVIII de un pensamiento constitucional británico antihistoricista (Paine es un buen ejemplo) ${ }^{6}$. Tampoco lo sería reducir el pensamiento constitucional francés y español de ese siglo al iusnaturalista y revolucionario, pues ello supondría no tener en cuenta, en el caso de Francia, el muy interesante pensamiento historicista y reformista desde Montesquieu a los "notables", con indudable influjo en el constitucionalismo más conservador de la Restauración ${ }^{7}$; ni tampoco, en el caso de España, el pensamiento de Jovellanos, el más importante teórico de la "Constitución histórica", cuya influencia en este país a lo largo del siglo XIX fue decisiva ${ }^{8}$.

Pero, con carácter general, puede afirmarse que mientras el constitucionalismo historicista, de particular influencia en la Gran Bretaña, quiso acomodar las doctrinas constitucionales a las normas e instituciones que conformaban una determinada Constitución histórica, más o menos viva, el constitucionalismo racionalista, cuyo prototipo es el francés del siglo XVIII, pretendió hacer justamente al revés: modelar las normas y las instituciones constitucionales de acuerdo con unas doctrinas diseñadas ex novo previamente y haciendo tabula rasa del derecho y de las instituciones vigentes?.

Pero al historiador del constitucionalismo no le basta con ensamblar la perspectiva normativo-institucional con la doctrinal, sino que además debe conectar las normas, las instituciones y las doctrinas constitucionales con la sociedad en la que se insertan. Una conexión que le obliga a conocer, aunque sólo sea de forma instrumental, la realidad histórica en su conjunto, sobre todo la política y la intelectual. Volviendo a los ejemplos antes citados, tanto el concepto de soberanía del Parlamento que sostuvo Hume como el de soberanía nacional que defendieron Sieyes y los liberales españoles en Cádiz, no

6 Sobre Paine, vid, mi monografía Sistema de gobierno y partidos politicos: de Locke a Park, Centro de Estudios Políticos y Constitucionales (CEPC), Madrid, 2002, pp. 99 y ss, que acaba de traducirse al italiano con el título Governo e partiti nel pensiero británico ( 1690-1832), Giuffrè, Milán, 2007.

7 Cfr. mi artículo Constitución histórica y anglofilia en la Francia pre-revolucionaria (la alternativa de los "Notables"), publicado primero en VV. AA, "Visión Iberoamericana del Tema Constitucional, Fundación Manuel García- Pelayo, Caracas, 2003, pp. 23-39, y más tarde en el "Giornale di Storia Costituzionale", n 9, 2005, pp. 53-62.

8 Cfr. mi artículo La doctrina de la Constitución Histórica: de Jovellanos a las Cortes de 1845, "Revista Española de Derecho Político” (REDP), no 39, Madrid, 1995, pp. 45-79. Este artículo se ha incluido en mi reciente libro Política y Constitución en España (1808-1978), CEPC, Madrid, 2007, prólogo de Francisco Rubio Llorente.

9 Por eso, el momento de partida para estudiar la historia constitucional de una nación no puede ser la fecha en que se aprobó su primer texto constitucional. El historiador del constitucionalismo debe estudiar también las doctrinas constitucionales que le precedieron, sin las cuales este texto no se comprende plenamente. Desde este punto de vista, la historia constitucional de los Estados Unidos no comienza en 1787, ni la francesa en 1789, ni la española en 1808. Antes de esas fechas se produjo un debate constitucional que el historiador del constitucionalismo debe conocer y estudiar. En lo que concierne al vínculo entre doctrinas políticas e historia constitucional resultan de interés las observaciones de Alfred Dufour en Considérations inactuelles sur les rapports entre doctrines politiques e bistoire constitutionnelle, "Giornale di Storia Costituzionale ", n' 2, 2001, pp. $15-20$. 
pueden entenderse más que en el contexto de la lucha política e intelectual en que tales conceptos se formulan. En el caso de Hume, en pugna con los tories jacobitas, aferrados a la soberanía de los reyes, y con algunos sectores whigs, defensores de las tesis lockeanas de la soberanía del pueblo. En el caso de Sieyes, en liza con los "notables", que deseaban mantener la soberanía del rey, aunque limitada en su ejercicio por las antiguas leyes fundamentales de la monarquía. Y, en fin, en el caso de los liberales doceañista, en controversia con los diputados realistas, agrupados en torno a la tesis escolástica de la soberanía compartida entre el rey y el reino, y con los diputados americanos, quienes defendían la soberanía de las provincias ultramarinas, de acuerdo con una curiosa mezcla de doctrinas procedentes de las Leyes de Indias y de Francisco Suárez, del iusnaturalismo germánico (Grozio, Puffendorff) y de Rousseau.

\section{LAS NORMAS Y LAS INSTITUCIONES CONSTITUCIONALES: EL TEXTO Y EL CONTEXTO, LA PERMANENCIA Y EL CAMBIO}

Al estudiar una Constitución- o cualquier otra norma materialmente constitucional- el historiador del constitucionalismo debe tener en cuenta que su objeto de estudio es un derecho no vigente. Incluso cuando analiza una Constitución histórica todavía en vigor- por ejemplo la británica o la de los Estados Unidos de América- lo que debe interesarle es su génesis y desarrollo, no el resultado final al que ha llegado, que es el objeto de estudio del constitucionalista, lo que no es óbice para que el estudio de la Historia constitucional pueda resultar muy útil también para explicar y comprender mejor el constitucionalismo vigente. Si el constitucionalista se pregunta por el sentido que actualmente cabe darle a esta Constitución, el historiador del constitucionalismo debe preguntarse ante todo cómo fue interpretada y aplicada en el pasado por los protagonistas de la acción política (jefes de Estado, ministros, parlamentarios) y por los distintos operadores jurídicos (jueces y doctrina científica), además de interrogarse por su eficacia en la protección de los derechos fundamentales de los ciudadanos. Lo que no impide que el historiador del constitucionalismo lleve a cabo también su propia interpretación gramatical, teleológica y sobre todo sistemática de los textos normativos que estudia, poniendo en relación unos preceptos con otros, con el objeto de desvelar su lógica interna, el sentido de esos textos: la voluntas legis y no sólo la voluntas legislatoris.

En lo que concierne a las instituciones, el historiador del constitucionalismo debe esforzarse por advertir sus transformaciones por encima de su aparente quietud ${ }^{10}$. A este respecto cobra una especial relevancia el estudio de las

10 Merece la pena, a este respecto, traer a colación estas palabras de Francisco Tomás y Valiente: "el problema que el historiador de las instituciones habrá de resolver consiste en descubrir, dentro del largo período de duración de las instituciones estudiada, su propia dinámica, su peculiar ritmo de cambio, apenas perceptible, por lo general, si se la contempla deprisa o si se pretende me- 
convenciones constitucionales, mediante las cuales se fueron modificando las instituciones sin que necesariamente se alterasen las normas escritas que las regulaban $^{11}$. La importancia de las convenciones es particularmente relevante en la historia constitucional de la Gran Bretaña, en donde, como es bien conocido, la transferencia del poder del monarca a un Gabinete responsable sobre todo ante los Comunes, se fue llevando a cabo, desde comienzos del siglo XVIII, mediante un conjunto de convenciones o reglas no escritas, sin que se modificase la legislación aprobada por el Parlamento, al menos hasta comienzos del siglo xx, aunque no es menos cierto que esta transferencia de poder, que supuso el tránsito de la monarquía constitucional a la monarquía parlamentaria, intervinieron también los jueces ${ }^{12}$.

Esas convenciones desempeñaron también un destacadísimo papel en otras monarquías constitucionales europeas del siglo XIX, como la belga. Sin embargo- y eso es lo que ahora interesa resaltar - no siempre los estudiosos del Derecho constitucional destacaron su importancia. El ejemplo más significativo es el de Blackstone, sin duda el jurista inglés más influyente del siglo XVIII, quien mantuvo respecto de ellas un elocuente silencio, que contrasta con la actitud de Burke. Pero más significativo resulta comprobar que incluso muchos historiadores del constitucionalismo inglés pasaron por alto estas reglas no escritas, que transformaron de forma decisiva el acuerdo constitucional de 1688. En realidad, con la excepción de Hume, en estas convenciones no insistió la historiografía británica hasta comienzos del siglo XIX. Todavía en 1827, por citar un ejemplo, Henry Hallam, en su The Constitucional History of England, seguía afirmando la continuidad constitucional inglesa desde la revolución de 1688, a la vez que consideraba a la Carta Magna un documento de igual naturaleza que el Bill of Rights. Frente a esta actitud, algunos historiadores románticos, como James MacKinstosh y William Betham, insistieron en el cambio constitucional que se había ido llevando a cabo en la Gran Bretaña desde 1688, más allá de su aparente continuidad. No obstante, quien insistió con más agudeza en esta nueva perspectiva de la historia constitucional no fue propiamente un historiador, sino un jurista, hoy olvidado, incluso por los propios ingleses: J. J. Park, en quien se aprecia tanto el influjo de Savigny como el de Comte. En su libro The Dogmas of the Constitution, publicado en 1832, Park analiza de forma muy aguda las transformaciones constitucionales que se fueron produciendo desde la revolución de 1688, denunciando las interpretaciones

dirlo con el reloj de la bistoire evenementielle. Pero no hay instituciones inmóviles ni inmutables" Historia del Derecho e Historia, en Obras Completas, CEC, Madrid, 1997, IV, p. 3294.

11 Entre una abundante bibliografía, vid., la clásica obra de G. Marshall, Constitutional Conventions, the Rules and Forms of Political Accountability, Oxford, Clarendon Press, 1984, así como la de P. Avril, Les conventions de la constitution, coll. Léviathan, Paris, PUF, 1997.

12 Me he ocupado de ello en El constitucionalismo británico entre dos revoluciones (16881789), en Joaquín Varela Suanzes- Carpegna (Coordinador), Modelos constitucionales en la bistoria comparada, "Fundamentos. Cuadernos monográficos de Teoría del Estado, Derecho público e Historia constitucional", $\mathrm{n}^{\circ}$ 2, Junta General del Principado de Asturias, Oviedo, 2000, pp. 25-96; así como en la obra, ya citada, Sistema de gobierno y partidos políticos: de Locke a Park. 
tradicionales, de Montesquieu, De Lolme y sobre todo de Blackstone, inspiradas más en la letra que en el espíritu de la Constitución, en la "constitución formal" que en la "Constitución real»— una distinción clave, sobre la que volveré más tarde-, lo que había llevado a estos autores a reparar en la permanencia de las normas y de las instituciones, sin tener en cuenta el profundo cambio que en ambas habían llevado a cabo las reglas no escritas acordadas por los protagonistas de la política ${ }^{13}$.

En lo que concierne al estudio histórico de las instituciones, merece la pena insistir en la importancia- también en la dificultad- que encierra el estudio de la Corona, nomen iuris de la jefatura de Estado monárquica en varias naciones, entre ellas la Gran Bretaña y España, cuyo titular es el rey o la reina. Al estudiar la Corona, el historiador debe, desde luego, describir su posición constitucional a partir de su status normativo y de las convenciones que se fueron imponiendo con el transcurso del tiempo, con el propósito de analizar, por ejemplo, su participación, de iure y de facto, en la función legislativa o en la dirección política del Estado, poniendo de relieve el uso o el desuso (la desuetudo) del veto regio a los proyectos de ley aprobados por el Parlamento. Pero además de eso, resulta indispensable que se ocupe de mostrar la función integradora de la Corona, en la que insistió de forma muy penetrante Rudolf Smend ${ }^{14}$, como símbolo y encarnación o representación del Estado (una función integradora más acusada en un rey que en un Presidente de la República), lo que requiere examinar el papel del monarca en el seno de la vida política nacional y su arraigo social, sin olvidarse de su papel moderador o arbitral ${ }^{15}$.

En definitiva, pues, cuando el historiador del constitucionalismo analiza las normas y las instituciones debe poner de relieve su permanencia, pero también su cambio. Un cambio que no sólo se lleva a cabo mediante la reforma del texto constitucional, sino merced a las reformas de otras normas materialmente constitucionales, así como a través de las convenciones y en virtud de la jurisprudencia de los tribunales, sin necesidad de que haya habido una reforma expresa de texto normativo alguno. Dicho con pocas palabras, el historiador del

13 Cfr. mi Estudio Preliminar a J. J. Park, Los Dogmas de la Constitución, traducción al español a cargo de Ignacio Fernández Sarasola, Istmo, Madrid, 1999, pp. 16, 30 a 43 y 5, así como mi mencionado estudio La soberanía en la doctrina británica (de Bracton a Dicey). Como pongo de relieve en estos trabajos, esta manera de aproximarse al constitucionalismo, en el que un poco antes que Park habían insistido también Thomas Erskine y Lord John Russell, tendría después un brillante desarrollo en el ámbito de la teoría político-constitucional (Henry G. Grey, Stuart Mill y Walter Bagehot), en el de la Filosofía del Derecho ( Austin), en el Derecho Constitucional ( Dicey) y en la propia Historia constitucional ( Maitland).

14 Cfr. Rudolf Smend, Verfassung und Verfassungsrecht (1928), traducción española Constitución y Derecho Constitucional, CEC, Madrid, 1985, especialmente pp. 73-74, 144-145, 152154, 160-161, 169-173, 204 y 221.

15 Estas funciones simbólicas, representativas y arbitrales del monarca, en las que ya había insistido agudamente Benjamín Constant, se recogen en el artículo 56 de la vigente Constitución española, que dice así: "El Rey es el Jefe del Estado, símbolo de su unidad y permanencia, arbitra y modera el funcionamiento regular de las instituciones, asume la más alta representación del Estado español en las relaciones internacionales, especialmente con las naciones de su comunidad histórica, y ejerce las funciones que le atribuyen expresamente la Constitución y las leyes". 
constitucionalismo debe tener en cuenta tanto la Vefassungswandlung como la Verfassungänderung, esto es, las "reformas constitucionales" y las "mutaciones Constitucionales" ${ }^{16}$.

\section{DOCTRINAS Y CONCEPTOS CONSTITUCIONALES: SU CONTENIDO JURÍDICO}

El estudio histórico de las doctrinas constitucionales plantea problemas de muy distinta naturaleza en función del tipo de fuentes a través de los cuales tales doctrinas se expresan. No es lo mismo estudiar un folleto destinado a la acción politica, como Thoughts on the Cause of the Present Discontents (1770), de Burke, y La Monarchie selon la Charte ( 1816), de Chateaubriand, que una publicación de carácter académico, como la Algemeine Staatslehre (1900), de Jellinek. Los dos primeros, como es lógico, exigen que el historiador del constitucionalismo ponga el acento en el ambiente político, mientras que este último requiere hacer hincapié sobre todo en el contexto intelectual y científico. En cualquier caso, en los tres textos mencionados el historiador se encuentra con una doctrina ya elaborada. No ocurre así, en cambio, cuando se trata de estudiar los debates parlamentarios, que suministran una información muy importante, sobremanera cuando los Parlamentos tienen una naturaleza constituyente, como la Convención de Filadelfia, la Asamblea francesa de 1789 o las Cortes de Cádiz. En estos casos, después de una atenta lectura de los debates parlamentarios, corresponde al historiador reconstruir la doctrina constitucional que se expone en esos debates, para lo que resulta muy útil agrupar a los miembros de estas Asambleas en "tendencias constitucionales" (que no coinciden necesariamente con los partidos políticos), de acuerdo con las propuestas que defendieron respecto de la organización del Estado y de sus relaciones con la sociedad. Unas propuestas que conforman auténticos "modelos constitucionales" en liza, que el historiador debe también examinar ${ }^{17}$.

16 La distinción entre ambos conceptos está presente en Laband y Jellinek. De este último puede verse la versión española, a cargo de P. Lucas Verdú y C. Förster, Reforma y mutación de la Constitución, CEC, Madrid, 1991; pero el clásico libro sobre la materia es el de Hsü-Dau-Lin, Die Vefassungswandlung, Berlin und Leipzig, 1932, traducido al español por los mismos autores con el título Mutación de la Constitución, Instituto Vasco de Administración Pública, Oñate, 1998.

17 De acuerdo con los conceptos histórico-constitucionales de "tendencias" y "modelos", estudié las doctrinas defendidas en las Cortes de Cádiz en mi citado libro La Teoría del Estado en los orígenes del constitucionalismo hispánico. Lo hice también en relación a la Asamblea francesa de 1789 en Mirabeau y la monarquía o el fracaso de la clarividencia, "Historia Contemporánea", $\mathrm{n}^{\circ}$ 12, Bilbao, 1995, pp. 230-245. Utilizo, asimismo, el concepto de "modelo constitucional" en Las cuatro etapas de la bistoria constitucional comparada, que sirvió de Introducción al libro Textos básicos de la historia constitucional comparada, CEPC, Madrid, 1988, pp. XVII-XXX. Este concepto me ha servido también para concebir y coordinar el libro colectivo, ya citado, "Modelos constitucionales en la historia comparada". Por último, he utilizado el concepto de "modelo" en La construcción del Estado en la España del siglo XIX una perspectiva constitucional), "Cuadernos de Derecho Público", no6, Enero- Abril, 1999, pp. 71-81. Un artículo este último que se ha incluido en mi citado libro Política y Constitución en España (1808-1978). 
Dentro de las doctrinas constitucionales interesa muy particularmente al historiador examinar los conceptos que puedan formularse, de manera expresa o implícita. Una cosa es la doctrina constitucional, por ejemplo de Burke, de Chateaubriand y de los "patriotas" franceses de 1789, y otra distinta los conceptos de "Constitución", de "monarquía "y de "partido político" que estos autores y esta tendencia sostuvieron. Las doctrinas constitucionales se componen de un conjunto más o menos sistemático de ideas en torno a la organización del Estado, elaboradas por un autor o una "tendencia constitucional". Los conceptos constitucionales son mucho más precisos y concretos, se reflejan en un término o palabra y su paternidad es mucho más variada, puesto que pueden formularlos todos los protagonistas de la vida política y jurídica: monarcas, ministros, parlamentarios, jueces, publicistas y profesores, además de expresarse mediante una variedad enorme de fuentes, como los textos normativos, las actas de un Consejo de ministros, los discursos parlamentarios, la jurisprudencia de los tribunales, la prensa y los opúsculos políticos, los manuales académicos, las enciclopedias y los diccionarios e incluso documentos anónimos, como panfletos clandestinos.

Las doctrinas y los conceptos constitucionales pueden tener un mayor o menor contenido jurídico. Desde este punto de vista, es preciso distinguir entre los países anglosajones o de common law y los europeos continentales. En los primeros, la reflexión intelectual sobre el Estado constitucional ha estado más apegada al ordenamiento jurídico, a veces formalmente muy estable, como en la Gran Bretaña y los Estados Unidos. Los ya citados Commentaries de Blackstone, de gran influjo también al otro lado del Atlántico, son a este respecto paradigmáticos. Por otro lado, en los países anglosajones la juridificación de las doctrinas y de los conceptos constitucionales se debe en gran medida a que los jueces son auténticos creadores de derecho- también de derecho constitucional- y no sus meros intérpretes y aplicadores, como ocurre en la Europa continental. La Constitución británica, como es bien sabido, es en buena medida una judge-made constitution. Al interpretarla y aplicarla, por ejemplo en materia de derechos individuales, las sentencias judiciales (su ratio decidendi, no los obiter dicta) van conformando una doctrina y sentando unos precedentes, a los que deben atenerse posteriormente los jueces para resolver casos similares. En los Estados Unidos la jurisprudencia de la Supreme Court tuvo un papel decisivo en esta labor juridificadora. Baste recordar el concepto de judicial review of legislation, que acuñó el juez Marshall, Presidente de este Tribunal, en 1803, de acuerdo con algunos preceptos del la propia Constitución de 1787. Un concepto en el que se concretaba la doctrina- defendida antes por Hamilton en The Federalist- de la supremacía de la Constitución federal sobre las demás leyes y normas del ordenamiento, tanto las federales como las de los Estados miembros de la Federación, lo que suponía, a la vez, apuntalar el propio Estado Federal ${ }^{18}$.

18 Del concepto de Constitución como norma suprema me ocupo en Riflessioni sul concetto di rigidità costituzionale, "Giurisprudenza Costituzionale", Anno XXXIX, fasc.5, 1994, pp. 3313- 
En la Europa continental, en cambio, la juridificación de los conceptos político-constitucionales comenzó en la segunda mitad del siglo xIX, por obra de la doctrina científica, aunque no debe desdeñarse en absoluto la labor llevada a cabo por algunos tribunales, incluso años antes. Citaré a este respecto un ejemplo. La doctrina político-constitucional de Benjamín Constant sobre el poder neutro, expuesta durante la Restauración, implicaba, como es bien sabido, distinguir entre el monarca, como jefe del Estado, y el Gobierno, además de entre éste y la Administración. Pues bien, tales premisas - en las que insistieron más tarde Thiers, Prevost — Paradol y Bagehot — sentaron las bases para que el Conseil d'Etat distinguiese, también durante la Restauración, entre los actos jurídicos del Gobierno y sus actos políticos, así como, más tarde, entre la función ejecutiva del Gobierno y su actividad política o extra iuris ordinem, lo que resultó decisivo para la formación del Derecho administrativo francés y, a la vez, para la delimitación del concepto de "función de gobierno" o de "indirizzo politico", en el que insistiría la doctrina constitucional italiana del siglo XX (Crisafulli, Lavagna, Virga y Mortati).

No obstante, el protagonismo en la labor juridificadora de las doctrinas constitucionales en la Europa continental no recayó en la jurisprudencia, sino en la doctrina científica. Si hasta entonces en estos países habían sido sobre todo los filósofos y los políticos los que se habían ocupado de reflexionar sobre el Estado constitucional en ciernes ( filósofos y políticos que, por supuesto, habían tenido también un papel decisivo en la Gran Bretaña y los Estados Unidos), a partir de la segunda mitad del siglo XIX, consolidado ya ese Estado en la Europa occidental, son los juristas, y muy particularmente los profesores de Derecho, los que se ocupan predominantemente de esta reflexión ${ }^{19}$. Las doctrinas y los conceptos político-constitucionales (como el de Rechstaat, acuñado por Von Mhöl, siguiendo a Kant, y réplica del anglosajón rule of law) se fueron depurando y transformando en doctrinas y conceptos jurídico-constitucionales, pese a que la Constitución careciese en Europa de valor normativo hasta el siglo xx. Esta labor juridificadora, en la que se enmarca la creación de la Ciencia del Derecho Constitucional como un rama de la ciencia jurídica, estuvo impulsada muy especialmente por el positivismo jurídico, que dominó la reflexión constitucional europea hasta los años treinta del siglo xx. A tenor de este proceso purificador se articularon auténticas "dogmáticas» jurídico-constitucionales, desligadas deliberadamente de la realidad política y social, con la pretensión de explicar e interpretar el ordenamiento constitucional de una nación, como en el ámbito del De-

3338, recogido más tarde en Alessandro Pace/ Joaquín Varela La rigidez de las Constituciones escritas, CEC, Madrid, 1995. Sobre este asunto, vid. asimismo, Roberto Blanco Valdés, El valor de la Constitución, Alianza Editorial, Madrid, 1994; y Mauricio Fioravanti, Costituzione, Il Mulino, Bolonia, 1999; traducción española: Constitución. De la antigüedad a nuestros días, Trotta, Madrid, 2000.

19 En estos extremos insisto en ¿Qué ocurrió con la ciencia del Derecho Constitucional en la España del siglo XIX?, "Anuario de Derecho Constitucional y Parlamentario", n 9, 1997, pp. 71-128, Murcia, 1997; y "Boletín de la Facultad de Derecho", UNED, n 14, Madrid, 1999, pp. 93-168. Este trabajo se recoge en mi citado libro Política y Constitución en España (1808-1978). 
recho privado se hacía para explicar la propiedad o la familia merced a los conceptos suministrados en buena medida por el Derecho Romano. En tales planteamientos se basaron las grandes construcciones doctrinales de Gerber, Laband y Jellinek en Alemania, de Orlando en Italia, de Dicey en la Gran Bretaña y, más tardíamente, de Esmein y Carré de Malberg en Francia.

La crisis del positivismo jurídico que podríamos llamar "clásico" - a quien, con todas sus insuficiencias, se debe la creación del moderno Derecho Constitucional - sobre todo a partir de los años treinta del pasado siglo, entorpeció el proceso juridificador de las doctrinas y los conceptos constitucionales, que volvieron a reinsertarse en su contexto histórico, social y político, como defendieron no sólo algunos historiadores, por ejemplo Otto Hintze ${ }^{20}$ y sobre todo Otto Brunner ${ }^{21}$, sino también no pocos cultivadores del Derecho Constitucional, entre ellos Carl Schmitt ${ }^{22}$, uno de los más agudos críticos del positivismo jurídico y, en particular, del normativismo kelseniano. Es indudable que la crítica al positivismo jurídico por parte de estos autores (y de otros muchos, como el ya mencionado Smend) resulta en buena medida muy útil todavía hoy para la Historia constitucional, aunque no necesariamente lo sea para el Derecho Constitucional ni mucho menos para la interpretación judicial del derecho ${ }^{23}$. En cualquier caso, lo que hora importa subrayar es que los ataques al positivismo jurídico, aunque debilitaron la labor juridificadora de la doctrina constitucional, no impidieron que esa labor siguiese adelante, impulsada incluso por autores muy alejados del positivismo, como pone de relieve el mencionado concepto de indirizzo politico. Es preciso tener en cuenta, además- y baste ahora mencionar este fenómeno, pues su examen nos llevaría muy lejos-, que la juridificación de los conceptos político-constitucionales cobró nuevo impulso en la Europa del siglo xx a resultas de la articulación de los Tribunales constitucionales en diversos países.

\section{LA INTERPRETACIÓN DE LAS DOCTRINAS Y LOS CONCEPTOS CONSTITUCIONALES: «PRESENTISMO" Y "ADANISMO"}

Me gustaría, por último, señalar que, sea cual fuere la fuente a través de la cual se expresen las doctrinas y los conceptos constitucionales, y con inde-

20 Cfr. Otto Hintze, Staat und Verfassung. Gesammelte Abhandlungen zur allgemeinen Verfassungsgeschichte, Göttingen, Vandenhoek und Ruprecht, 1962.

21 Cfr. Otto Brunner, Land und Herrschaft, 1939. Sobre el gran historiador austríaco, vid. Helmut Quaritsch, Otto Brunner ou le tournant dans l'écriture de l'Histoire constituionnelle allemande, "Droits ", n' 22, 1995, pp. 145-162.

22 Cfr. Por ejemplo, el trabajo de Carl Schmitt, bajo el reconocido influjo de Otto Brunner, Staat als ein konkreter, an eine geschichtliche Epoche gebundener Begriff, en Verfassunsrechliche Aufsätze, 1958. Sobre la actitud de Schmitt ante la Historia constitucional, vid. Fulco Lanchester, Carl Schmitt e la storia costituzionale, "Quaderni Costituzionale", n 3, 1986, pp. 487-510.

23 En realidad, es perfectamente coherente aceptar la validez del positivismo jurídico-incluso del normativismo kelseniano_ en el ámbito de la Teoría General del Derecho y del Derecho Constitucional y reconocer a la vez su escaso o nulo valor para la Historia Constitucional. 
pendencia de su mayor o menor contenido jurídico, el principal riesgo que debe evitar el historiador del constitucionalismo es el de interpretar esas doctrinas y conceptos desde el presente en vez de hacerlo desde la época en que tales conceptos surgieron. Dicho en pocas palabras: su principal riesgo es el presentismo, en el que han incurrido numerosos constitucionalistas, que suelen acercarse al constitucionalismo del pasado no tanto para comprenderlo y explicarlo, cuanto para justificar sus propias elaboraciones doctrinales. Así ha ocurrido, por citar un ejemplo señero, con Raymond Carré de Malberg, a mi juicio el más brillante exponente de la Ciencia del Derecho Constitucional en Francia, quien en su espléndida y sutilísima Contribution a la Théorie Générale de l'Etat, al extenderse sobre el concepto de soberanía en la Revolución francesa, atribuye a la doctrina constitucional de esa época una nítida distinción conceptual entre soberanía nacional y soberanía popular ${ }^{24}$, que en realidad no se estableció con la nitidez y las consecuencias que Carré de Malberg señala hasta la monarquía de Julio ${ }^{25}$.

El presentismo es la causa de muchos anacronismos, extrapolaciones y prolepsis o anticipaciones al examinar las doctrinas y los conceptos constitucionales. Y en él han incurrido también no pocos historiadores de las doctrinas políticas - algunos tan agudos como Otto von Gierke ${ }^{26}$, a veces más atentos al estudio de un repertorio de ideas invariable a lo largo del tiempo, que a ver el tiempo de tales ideas, es decir, su historicidad y, por tanto, su diverso sentido y propósito. Un peligro contra el que nos han alertado diversos autores a lo largo del siglo xx, como el mencionado Otto Brunner, codirector, junto a Reinhart Kosselleck y a Werner Conze, del Diccionario de conceptos bistóricos básicos en lengua alemana, elaborado desde 1972 hasta 1997 y sin duda el logro más brillante de la Begriffgeschichte, promovida años antes por la hermeneútica de Hans- Georg Gadamer y centrada sobre todo en la proyección de los conceptos políticos en la praxis social ${ }^{27}$. Muchas de las premisas de esta Begriff-

24 Cfr. Contribution a la Théorie Générale de l'Etat, Paris, Sirey, 1920-1922, vol 2. pp. 152197.

25 En este extremo insiste Guillaume Bacot en su estudio Carré de Malberg et l'origine de la distinction entre souveraineté du peuple et souverainité nationale, editions du CNRS, Paris, 1985, passim, y sobre todo pp. 14-18, 164-165 y 177-182. Vid, asimismo, Christoph Schönberger, De la souverainité nationale à la souverainité du peuple : mutation et continuité de la Theorie Generale de l'Etat de Carré de Malberg ", en "Revue Française d'Histoire des Idées Politiques ", n 4, 1996, pp. 297-316.

26 Un autor que, pese a su frontal crítica al positivismo jurídico, sobre todo al de Laband, apenas se interesa por las circunstancias históricas de los conceptos que estudia, de ahí que incurra en extrapolaciones de bulto, por ejemplo cuando utiliza los conceptos de Estado y de soberanía en el contexto medieval, como hace en su conocida-y, por otro lado, espléndida-obra Die publicistichen Lehren des Mittelalters (1881), traducida al inglés por Maitland en 1900. Insisto en estos extremos en Politica y Derecho en la Edad Media, comentario al libro de Otto Von Gierke, Teorias políticas en la Edad Media,"Revista Española de Derecho Constitucional", no 49, 1977, pp. 335-351. Madrid, 1995.

27 Sobre esta escuela historiográfica, vid, en lengua española, Joaquín Abellán, Historia de los conceptos( Begriffsgeschichte) e historia social. A propósito del diccionario Geschichtliche Grundbegriffe, en S. Castillo (coor.), La historia social en España. Actualidad y perspectivas, Madrid, Siglo 
geschichte resultan muy útiles también para el historiador de los conceptos constitucionales. Y lo mismo puede decirse de los planteamientos metodológicos de los integrantes de la llamada "Escuela de Cambridge", en particular de Quentin Skinner y de J. G. A. Pocock, a quienes se debe una brillante revisión de la historia del pensamiento político, con el propósito de comprender mejor el sentido original de los textos del pasado y por consiguiente de las doctrinas que se expresan a su través. Si Skinner, como es bien sabido, es el creador del "método intencionalista", con su hincapié no tanto en la doctrina en sí, cuanto en el cómo y el para qué de la misma, Pocock ha insistido en el análisis de los conceptos en el marco de los lenguajes o discursos políticos, que conforman un determinado paradigma interpretativo ${ }^{28}$.

Siguiendo todos estos ejemplos - y algunos otros que podrían también ser útiles para el historiador de las doctrinas constitucionales, como los de la escuela francesa de Fontenay/ Saint Cloud, impulsora del Laboratoire de Lexicométrie et Textes Politiques - el historiador del constitucionalismo debe tener siempre muy presente al estudiar las doctrinas y conceptos constitucionales que su objetivo fundamental es explicar su génesis y desarrollo, cómo y para qué se crearon, de qué forma se interpretaron, en estrecha conexión con el contexto político, social e intelectual en el que surgieron y sin perder de vista las conexiones con otras doctrinas y conceptos anteriores y coetáneos, tanto nacionales como extranjeros, así como el impacto normativo, institucional e intelectual que tuvieron en su época y después.

Ahora bien, tal actitud no debiera entenderse nunca como una patente de corso para echar por la borda los conceptos elaborados por la propia Historia Constitucional, a partir de un proceso racionalizador de su objeto de estudio. De lo contrario el presentismo se sustituiría por un adanismo científico insostenible, que convertiría al historiador del constitucionalismo en una especie de Sísifo intelectual, obligado a cargar y descargar sus conclusiones una y otra vez, sin incorporarlas a su propio acervo terminológico. Dicho de otra forma: la necesidad de situar los conceptos constitucionales en su tiempo, no debe suponer

XXI, pp. 47-64; José Luis Villacañas y Faustino Oncina, Introducción a Kosselleck, Reinhart, y Gadamer, Hans-Georg, Historia y Hermeneútica, Paidos, Barcelona, 1997, pp. 9-53.

28 En el Estudio Preliminar a la traducción española del deslumbrante libro de Pocock, El momento maquiavélico (Tecnos, Madrid, 2002), Eloy García expone los planteamientos historiográficos de este autor, su enorme influjo en diversos ámbitos culturales y lingüisticos, así como las tesis de otros miembros de la "Escuela de Cambridge", como Skinner, pero también Peter Lasslett y John Dunn. Resulta también de interés la Presentación de Giussepe Buttà al estudio de Pocock, La ricostruzione di un impero, Sovranitá británica e federalismo americano, editada por Piero Lacaita Editore, Manduria, Bari, Roma, 1996, pp. IX-XXV, para el Laboratorio di Storia Costituzionale "Antoine Barvave", de Macerata. Una interesante crítica a las tesis de la Escuela de Cambridge, y también de la Begriffgeschichte, en el reciente trabajo de Lucien Jaume El pensamiento en acción: por otra bistoria de las ideas políticas, "Ayer", n 53, Madrid, 2004, pp. 109-130. En general, resulta de mucho interés este número de "Ayer", dedicado monográficamente a la "Historia de los Conceptos" y editado por Javier Fernández Sebastián y Juan Francisco Fuentes, así como el n 134 de la "Revista de Estudios Políticos", dedicado de forma monográfica a "Historia, Lenguaje y política", presentado por el mencionado Fernández Sebastián.. 
que la Historia constitucional, como todo saber que aspire a explicar científicamente una parcela de la realidad, renuncie a formular sus propios conceptos o categorías analíticas a la hora de examinar y exponer su objeto de estudio, como el de "modelo constitucional", al que antes me referí, que resulta útil para sistematizar la historia constitucional, tanto comparada como nacional ${ }^{29}$.

Por otro lado, el historiador del constitucionalismo al estudiar los conceptos constitucionales del pasado debe "traducirlos" al lenguaje actual, sin que nada le impida utilizarlos para explicar una realidad anterior, siempre y cuando ponga de relieve el carácter retrospectivo de esa aplicación. A este respecto, me parece oportuno subrayar que el historiador del constitucionalismo, sea cual su procedencia académica, debe poseer una sólida formación en Teoría de la Constitución. Un saber que puede definirse como una especie de Derecho constitucional común y general, elaborado a partir del examen de muy diversos ordenamientos constitucionales, vigentes o no, y que se ocupa, por citar algunos ejemplos, del concepto de Constitución, de las funciones que ésta cumple en el ordenamiento, de su elaboración, interpretación y reforma, así como de su defensa y garantía. De la misma manera que un historiador de la medicina o de la economía debe manejar con soltura los conceptos que le suministran la ciencias médicas y las económicas, un historiador del constitucionalismo debe conocer con precisión los conceptos elaborados por la Teoría de la Constitución, como el de "rigidez constitucional" o el ya mencionado de "mutación constitucional", que resultan sumamente útiles - en realidad imprescindiblesal historiador del constitucionalismo, aunque éste debe manejarlos con sumo cuidado, dejando claro su origen y procedencia.

Un ejemplo práctico - con el que voy a terminar estas reflexiones - puede ayudar a entender mejor lo que quiero decir con esta última observación. La distinción entre "constitución formal" y "Constitución material" la formula J. J. Park de forma explícita en el libro antes comentado, The Dogmas of the Constitution $^{30}$, aunque fue sobre todo el constitucionalista italiano Costantino Mortati quien la desarrollaría con gran brillantez en $1940^{31}$. Pues bien, esta distinción resulta de extraordinaria importancia para analizar el debate constitucional que tuvo lugar en la Gran Bretaña durante el siglo xviII, que giró en gran me-

29 O el de "principio estructural", como conjunto de preceptos que delimitan la forma de Estado, un concepto de uso muy extendido entre los constitucionalistas españoles actuales y que yo mismo he utilizado para clasificar las constituciones históricas de mi país y para encajar en ellas la vigente Constitución de 1978, al resultar más precisa que la habitual dicotomía "constituciones conservadoras" y "constituciones progresistas" Cfr. La Constitución de 1978 en la historia constitucional española, Revista Española de Derecho Constitucional", n 69, Septiembre-Diciembre de 2003, pp.31-67. Recojo este trabajo en mi citado libro Política y Constitución en España (1808-1978).

30 Cfr. mi citado Estudio Preliminara J. J. Park, Los Dogmas de la Constitución, pp. 27 y ss, así como el último capítulo de mi mencionado libro Sistema de Gobierno y partidos políticos (de Locke a Park).

31 Cfr. Costantino Mortati, La Costituzione in senso materiale, 1940, reimpresa en 1998 por Giuffre, Milán, 1998, con una premessa de Gustavo Zagrevelsky. Traducción española: La Constitución en sentido material, CEPC, Madrid, 2000, Estudio Preliminar y traducción de Almudena Bergareche Gros. 
dida entre los defensores de la Constitución formal ( Bolingbroke y Blackstone, entre otros), tal como la había delimitado Locke inmediatamente después de la revolución de 1688, y los defensores de la Constitución material ( como Walpole y Burke), que se había desarrollando a lo largo de esa centuria mediante convenciones y en la que destacaban como elemento central de esa Constitución el bipartidismo. ¿Es científicamente lícito que el historiador utilice esta distinción conceptual nacida en 1832 y desarrollada en 1940 para analizar y exponer la historia constitucional británica del siglo XVIII? Naturalmente que sí, al ser un útil instrumento analítico para estudiar esa época. Sencillamente, debe advertir que es posterior a la época que estudia ${ }^{32}$.

ABSTRACT. This work examines some problems that outlines the historical study-and, therefore, the one impermanence-of the norms, of the institutions and mainly of the constitutional doctrines.

32 Otro concepto que puede ser útil para clasificar las "tendencias constitucionales" en la historia constitucional - en particular en la española del siglo XIX - es el de "liberalismo de izquierda", pese a que durante esta época prefería hablarse de liberalismo "exaltado" o "avanzado". Sobre este concepto me extiendo en Retrato de un liberal de izquierda, recogido en Joaquín Varela Suanzes-Carpegna (coordinador), Álvaro Flórez Estrada (1766-1853). Economía, política, sociedad, Junta General del Principado de Asturias, Oviedo, 2004. He incluido este trabajo en mi reciente libro Asturianos en la politica española (pensamiento y acción), KRK ediciones, Oviedo, 2006. 